\title{
Failure analysis of two cold-working cutting tools. Case studies.
}

\author{
Carmen Medrea ${ }^{1,{ }^{*}}$, Leonidas Fragkos-Livanios ${ }^{2}$, Kostas I. Giannakopoulos ${ }^{1}$, and Dimitris \\ Statharas ${ }^{3}$ \\ ${ }^{1}$ University of West Attika, Department of Mechanical Engineering, 250 Thivon \& Petrou Ralli Ave. \\ 12244 Egaleo, Greece \\ ${ }^{2}$ University of West Attika, Department of Electrical and Electronics Engineering, 250 Thivon \& \\ Petrou Ralli Ave. 12244 Egaleo, Greece \\ ${ }^{3}$ University of Leicester, IMPaCT C/O Department of Engineering General Office, University Road, \\ LE1 7RH, Leicester, United Kingdom
}

\begin{abstract}
The study examines the dramatic drop in the efficiency of a cutting tool. The specific tool is part of machine used for cutting envelopes of paper for medical products packaging. Two similar pieces, selected after breaking down in service, were examined in depth. Historical data was collected. The tool temperature range during operation and the material hardness were measured. The fracture surfaces as well as the surrounding areas were carefully inspected. Chemical analysis was performed in order to identify the tool and coating materials. Results showed that components were made of different steels: D2 and Vanadis 6. The coating material also differs. Samples were selected and prepared for optical and electron microscopy. The condition of the cutting edges and the heat-treated microstructure were considered. Thickness, quality and homogeneity of the coatings were also inspected. Both tools failed by fatigue mode under different conditions. The fracture mechanism and its principal causes are discussed. The reasons of failure for both cutting tools are examined and compared. Poor designs associated with improper handling have led to the components breakage. Appropriate recommendations are given in order to eliminate similar situations and to improve the cutting performance.
\end{abstract}

\section{Introduction}

An engineering product is designed and manufactured to perform specific functions and serve certain needs over a predetermined period of time, named service life [1]. Cutting tools have been developed and used in all industrial applications. The cutting performance usually depends on tool design, selected material, manufacturing conditions, heat treatments, material to be processed, operating conditions and maintenance [2]. These factors determine the tool lifetime, which in turn affects its final price. When a tool stops operating prior to its expected service life, it is considered to have failed. Failure analysis examines the reasons of damage in order to report and restore any errors [3]. These causes 
may be classified as catastrophic (mainly attributed to faulty design and improper storage), manufacturing (due to defective material or manufacturing process) and operational defects (due to loading conditions, material handling, or reconditioning) [4]. Steel producers for tools develop low impurity and high performance materials to match the various market demands. Optimization of the manufacturing process improves the wear resistance, surface roughness and tool life [5]. New coating technologies are implemented in order to increase the service life of cutting tools [6]. Despite the continuous development of tool materials and the continuous improvement of production processes and tests, tools continue to fail. Occasionally they suffer from edge chipping and breakage during shearing under dynamic situation. Study of failures constitutes a useful guide for designers, manufacturers or users of the specific cutting tools.

Depending on their use, tool steels are intended for hot working, cold working, highspeed processing and measuring or testing instruments [7]. Cold work steels have been developed and used for more than a century [8]. This group of materials still has extensive use due to their specific properties; high hardness, high compressive strength, satisfactory tensile strength, wear resistance, good surface quality and good hardenability are commonly selected for cold working applications [9]. Failure of cold working steels has some particularities and suitable techniques have been suggested. Investigations on different worn-out tools have been conducted, regarding the failure mechanisms under specific conditions [10]. It has been shown that the premature failure of cold working tools is not always a consequence of their low operating capacity. Poor material selection or heat treatment method could affect negatively the working conditions [11]. The selection of new materials and appropriate heat treatments led to productivity improvement and delayed or even prevented failures [12]. High levels of hardness and adequate lubrication of contacting surfaces have been also recommended [13]. The decisive role of the sharp cracks formed due to poor EDM was underlined in a case of pipeline failure [14]. The elimination of critical defects inserted by EDM (electrical discharge machining) was studied focusing on machining conditions optimization [15]. The effect of a geometrical configuration on tool stress conditions was analysed and the role of finite edge radius on tool fracture during micro-cutting was underlined [16, 17]. An approach considering the tool wear has determined the optimal replacement time for metal cutting tools [6]. The concept of critical damage value (CDV) calculated through finite element method (FEM) simulation, was introduced in order to avoid failure in cold tooling [18]. Computational procedures were proposed to predict the cutting performance in the case of coated tools [19]. From the other, tool re-manufacturing prior to its mature failure is an economic and ecological alternative [20]. Increased tool service life could be also achieved by reducing the stress conditions of the tool during operation [21]. The tool cost in metal cutting has been estimated to reflect about $30 \%$ of the overall product cost [22], and therefore an increased tool service life can assure cost-effective production [23]. The analysis of every failure case-study could lead to a better understanding of failure mechanisms and decrease errors during production and handling of cutting tools.

This paper examines and compares the reasons of failure of two cutting tools; and provides suggestions in order to prevent similar damages.

\section{Experimental}

Two pieces were selected for examination. Historical data and recorded background were collected. The pieces were optically inspected. Chemical analysis was performed using optical transmition spectroscopy. Hardness was measured on the surface, along the entire length of the components and under its coating on the area with the greatest diameter. The coating was removed using a lathe. Samples were selected and cut by electro-discharge 
machining (EDM). The central stem of the tool was fragmented and samples were taken from the cross section. Representative samples were prepared for the examination of the cutting edge of the tool, the area close to the failure point and other parts of the stem. After suitable processing, they were investigated by means of optical microscopy. The condition of the cutting edges, the material structure and the quality of the heat treatment were examined. The fracture surfaces were subjected to scanning electron microscopy (SEM). Prior to examination, the specimens were cleaned using ultrasound sonicator bath. The thickness, quality and homogeneity of the coating were also inspected.

\section{Results and discussions}

Specific machines are used for cutting paper envelopes intended for medical products packaging. The cutting tools exhibit premature cutting incapacity. Two components brake down during operation. These pieces were collected and exanimated. The cutting tools have the same geometry and dimensions and are coated on most of their surface. Both tools broke at the second diameter change, next to the support points (Fig.1).

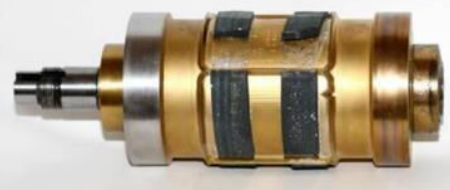

(a)

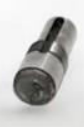

$\underline{50 \mathrm{~mm}}$

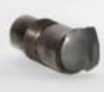

(b)

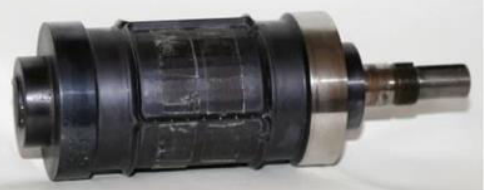

$\underline{50 \mathrm{~mm}}$

Fig. 1. General aspect of the two fractured tools.

The first tool (Fig.1, a) was made of AISI D2 steel and was coated with TiN (golden yellow colour). It fractured during operation on the right hand side. There was no information concerning the material and the coating of the second tool (Fig.1,b) which fractured at the same point, but on the left hand side. The damage occurred during assembly on the main machine, as the component was led on the bearings. It lasted longer, as compared to the first one.

Results from the chemical analysis (Table 1) confirmed the base and coating material of the first tool, i.e. AISI D2 steel and TiN respectively [24]. AISI D2 is one of the most common steels for cold working applications, widely used for cutting tools and forming dies [25]. The second tool was made of powder metallurgy steel (Table1). The composition found approached the chemical composition of Uddeholm VANADIS 6 tool steel, whereas the coating material was Al-TiN [26]. VANADIS 6 is a high performance PM cold working steel. Nowadays, many cold-working tool steels are produced by powder metallurgy (PM) methods due to their improved cutting performance [27].

Table 1. Chemical analysis of the tool materials

\begin{tabular}{|c|c|c|c|c|c|c|c|}
\hline & \multicolumn{6}{|c|}{ Element [\%] } \\
\hline & & $\mathbf{C}$ & $\mathbf{S i}$ & Mn & $\mathrm{Cr}$ & Mo & $\mathbf{V}$ \\
\hline \multirow{2}{*}{$\begin{array}{l}\text { AISI D2 } \\
\text { cutting tool }\end{array}$} & First cutting tool & 1.49 & 0.28 & 0.26 & 10.18 & 0.69 & 0.81 \\
\hline & $\begin{array}{c}\text { Nominal composition } \\
{[24]}\end{array}$ & $1.45-1.65$ & $0.3-0.4$ & $0.3-0.6$ & $11-13$ & $0.7-1.0$ & $0.7-1.0$ \\
\hline \multirow{2}{*}{$\begin{array}{c}\text { PM } \\
\text { VANADIS } 6 \\
\text { cutting tool }\end{array}$} & Second cutting tool & 2.15 & 1.20 & 0.43 & 6.44 & 1.59 & 4.27 \\
\hline & $\begin{array}{l}\text { Uddeholm nominal } \\
\text { composition [26] }\end{array}$ & 2.1 & 1.0 & 0.4 & 6.8 & 1.5 & 5.4 \\
\hline
\end{tabular}


According to the company, the components under examination are the only ones that failed by fracture. Nevertheless, cracks on the cutting surface have been detected frequently, resulting in premature tool replacement. The service life of the tools is estimated to 3,000,000 cuts for conventional steels and 5,000,000 cuts for powder metallurgy steels. It was estimated that the overall average number of goods produced was only $1,126,707$ units per tool, underling a dramatic reduction in tool performance $(62 \%$ for D2 tools and $77.5 \%$ for PM tools). Paper is a soft material, difficult to cut because it gets trapped easily and blocks the cutting system [28]. Continuous operation of a paper-cutting machine is only ensured when tolerance of the distance between the paper and the cutting parts is kept small and stable. When a tool ceases to cut due to wear and tear of its edges, it is sent for sharpening. The tools can be sharpened up to 10 times before their final removal from the production line. According to the working personnel, the tools are not subjected to stress relieving after sharpening and the effective number of cuts falls after every machining procedure. The machine operates 16 hours per day, at a cutting speed of 250-260 rotations per minute. Stress is not relieved between operating shifts or consecutive days.

The tools have a cylindrical complex shape with several changes in diameter. At the support points, where the tool failed, the cross-sectional reduction reaches approximately $70 \%$ (Fig.2)". Furthermore, optical inspection reveals lack of radii. The radius influences significantly both the cutting speed and the tool working life [29]. Its deficiency favours stress concentration, making points of change in diameter susceptible to fracture.

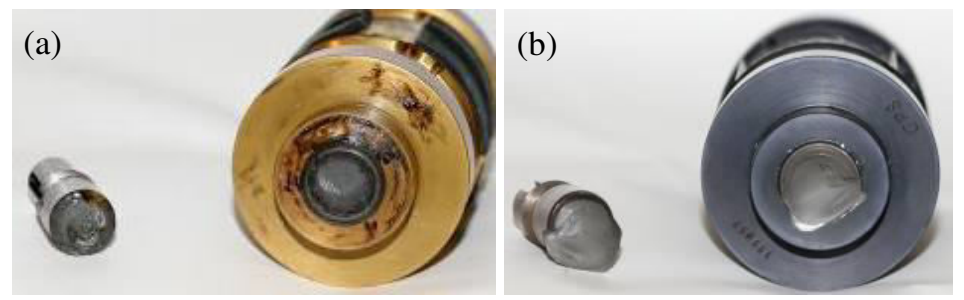

Fig. 2. Cross-sectional changing points close to the fracture area: (a) The first tool (D2 steel), (b) The second tool (Vanadis 6 steel).

The cutting tools usually operate at room temperature. The temperature measurements, carried out during operation, indicated values between $38^{\circ} \mathrm{C}$ and $45^{\circ} \mathrm{C}$. The highest temperatures were found in the centre of the tool; on the cutting edge areas. The temperature range is expected and should not affect negatively the tool efficiency.

Hardness measurements were carried out at several points along the tools axes (Fig. 3). The tool of AISI D2 steel exhibits a uniform hardness of 57-58 HRC, on both coated and uncoated areas (Table 2). There is no difference between the coated and uncoated areas even though the coating layer should increase the tool's surface hardness. This fact can be attributed to a very thin coating layer. On the contrary, the hardness of the PM tool is 6062HRC at the support points (positions 7, 8 and 10 in Fig. 3) and on the uncoated areas (positions 5 and 6 in Fig.3), whereas in the central coated area is 64-66HRC. In this case the coating increased the surface hardness, as expected.

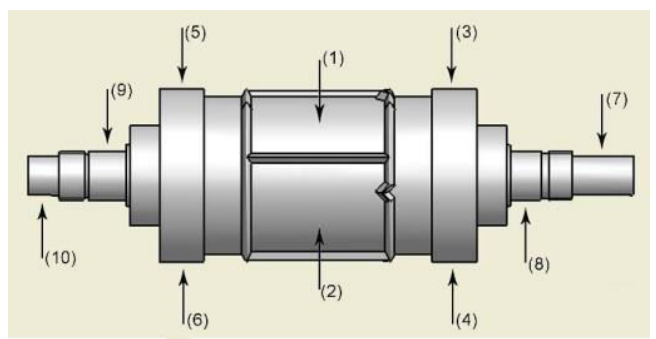

Fig. 3. Hardness measurement points. 
In fact, the smaller the cross section, the higher the hardness loss observed. In this case, the presence of coating is associated with much higher hardness values.

Table 2. Average hardness along the cutting tool

\begin{tabular}{|c|c|c|c|c|c|c|c|c|c|c|c|}
\hline \multicolumn{2}{|c|}{} & \multicolumn{10}{|c|}{ Hardness [HRC] } \\
\cline { 3 - 13 } & $(1)$ & $(2)$ & $(3)$ & $(4)$ & $(5)$ & $(6)$ & $(7)$ & $(8)$ & $(9)$ & $(10)$ \\
\hline \multirow{2}{*}{$\begin{array}{c}\text { AISI D2 } \\
\text { cutting tool }\end{array}$} & Coating covered & 57 & 58 & 58 & 57 & & & 58 & 57 & 58 & 58 \\
\cline { 2 - 12 } & $\begin{array}{c}\text { Without the } \\
\text { coating }\end{array}$ & & & & & 57 & 58 & & & & \\
\hline \multirow{2}{*}{$\begin{array}{c}\text { PM cutting } \\
\text { tool }\end{array}$} & Coating covered & 64 & 65 & & & 66 & 66 & 60 & 60 & 35 & 60 \\
\cline { 2 - 13 } & $\begin{array}{c}\text { Without the } \\
\text { coating }\end{array}$ & & & 60 & 60 & & & & & & \\
\hline
\end{tabular}

A dramatic decrease in hardness was detected at point 9 of PM tool. The specific area corresponds to the broken part of the shaft and actually represents the hardness of a ringshaped component. The ring, which was revealed during sample cutting (Fig. 4), was made of a different material. The particular configuration does not appear in the tool design drawings, indicating that its presence probably intended to remedy a machining mistake.

(a)

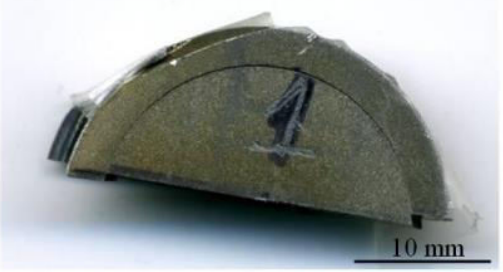

(b)

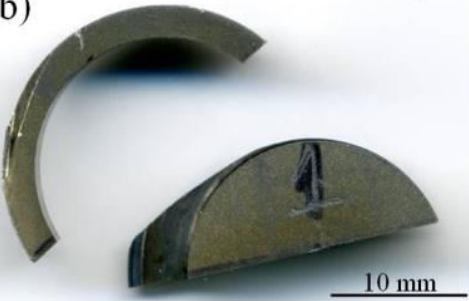

Fig. 4. Fragment from the support point of PM tool: (a) cut sample and (b) detached ring-shaped component.

Cross sectional samples from the cutting edges of both tools were used for metallographic analysis. The D2 cutting tool has a typical fine grained structure with characteristic carbides in the matrix (Fig. 5a). The coating is practically invisible, without any obvious diffusion zone. The PM tool exhibits a much more uniform and fine grained structure (Fig. 5b), with evident white layer and diffusion zone (Fig.5c). In both tools wear of the cutting edges exceeded the coating depth. Although the PM tool performed more cuts compared to the D2 one, its cutting edges exhibit better wear resistance.
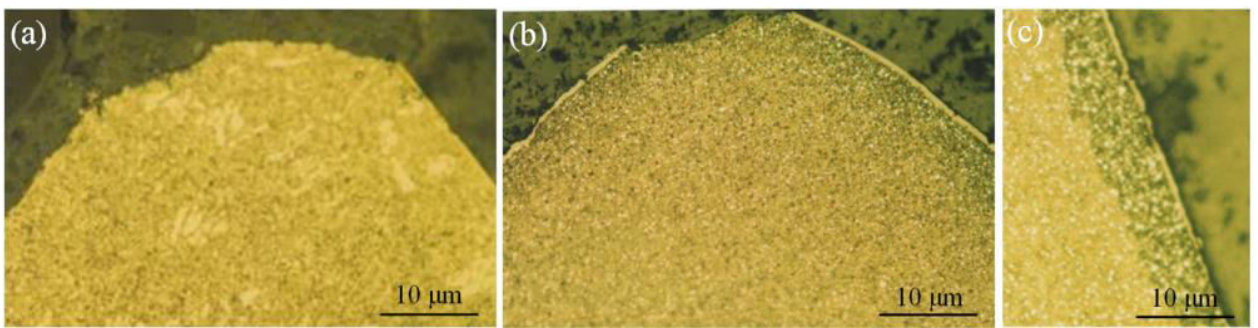

Fig. 5. Microstructure of the cutting edge cross section: (a) AISI D2 steel, (b) PM steel, (c) Detail of the PM steel cutting surface. The diffusion zone is clearly visible.

Closer SEM examination revealed a thin coating layer, 1-2 $\mu \mathrm{m}$ thick, in the case of D2 tool (Fig.6 a). The structure of the base metal is characteristic of hardened and tempered steel, with carbide concentrations (Fig.6 b). The thickness of the coating in PM tool is 7$8 \mu \mathrm{m}$ (Fig. $6 \mathrm{c}$ ), and the steel structure includes very thin, round and uniformly distributed carbides (Fig.6 d). 


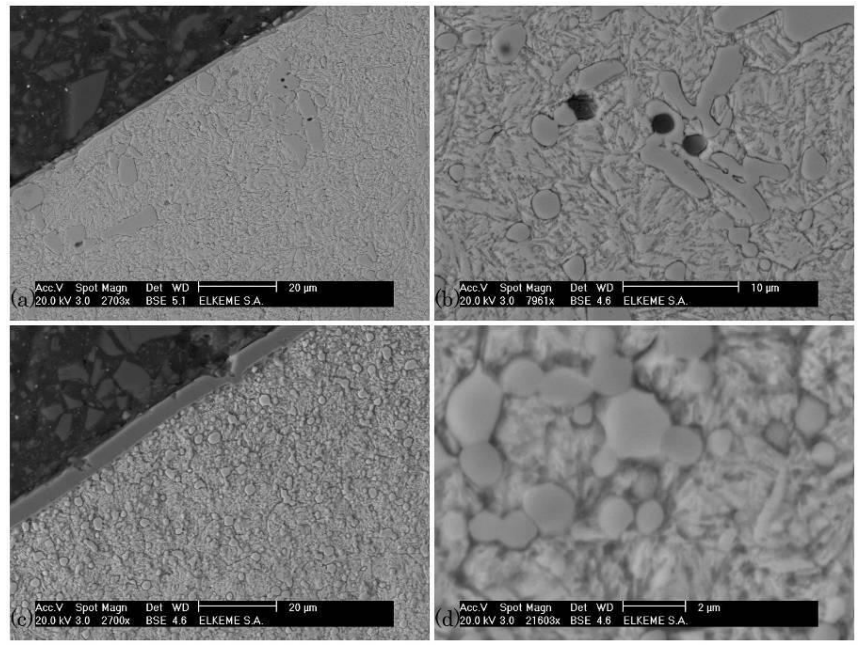

Fig. 6. SEM micrographs on the cross section of the cutting edges: (a,b) AISI D2 steel ,(c,d) PM steel.

Visual inspection of the fracture surfaces reveals significant differences in the fracture mode of the two pieces (Fig.7). D2 fragment has a wide rough surface. The fracture developed progressively in three stages, characteristic of fatigue. The crack initiated from the circumference and propagated uniformly towards the centre. During crack propagation part of the surface was seeped out (point I in Fig. 7a). In the centre, a crater occupying 30\% of the total section constitutes the area of final detachment, leading to gradation (point II in Fig. 7a). The absence of any reduction in area reveals that no plastic deformation prior to failure has occurred.

The fracture surface of the PM fragment is mainly smooth with only a narrow area, at the bottom right, being rough. Fracture developed in three stages is evidenced by the corresponding gradation. The left side area protrudes out the rest of the surface (Point I on Fig.7b). The fracture initiated from this area and followed a helical path. The smooth appearance is due to flattening by friction between the two surfaces, as the tool continued to function after breaking. The detachment represents approximately $10 \%$ of the total area, indicating that the cutting tool was not overloaded (Point II in Fig. 7b). Characteristic features such as beachmarks associated with fatigue can be observed (Fig. 7c).
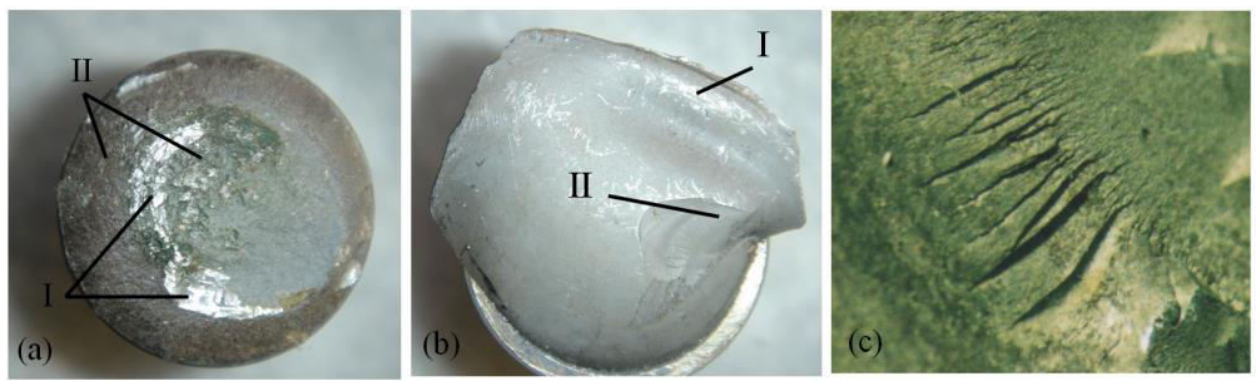

Fig. 7. Fracture surfaces of tool fragments: (a) D2 steel, (b) PM steel, (c) Detail of the PM steel fracture surface (image under stereoscope).

The two components were failed due to fatigue, but the evolution stages of the fracture differed. SEM fractography revealed the three fracture stages. The external area of D2 tool exhibits a thin brittle zone (Fig. 8a). The intermediate layer, subjected to high tension, was locally deformed and created folds (Fig. 8b). Although the folds resemble to beach-marks, they are created due to local high, periodic stresses. The central area experienced violent brittle fracture, creating a local crater, full of secondary cracks (Fig. 8c). 

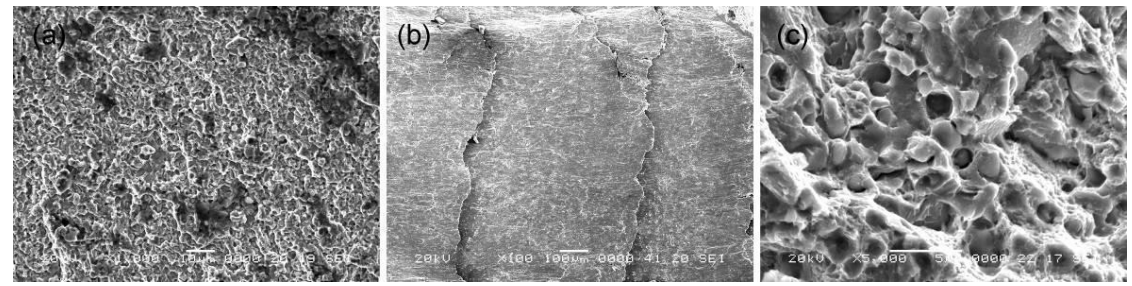

Fig. 8. SEM micrographs of D2 tool showing the three fracture stages: (a) External area, (b) Intermediate layer with folds, (c) Detachment area with crater and secondary cracks.

The corresponding fracture stages in PM tool, unlike D2, the fracture instantiates at a higher level than the rest of the surface (Fig. 9a). Upon crack propagation beach-marks are formed in the intermediate zone (Fig. 9b). As far as the detachment area is concerned, the high density of brittle aspects associated with absence of secondary cracks, is in accordance with the structure of hardened PM steel (Fig. 9c).
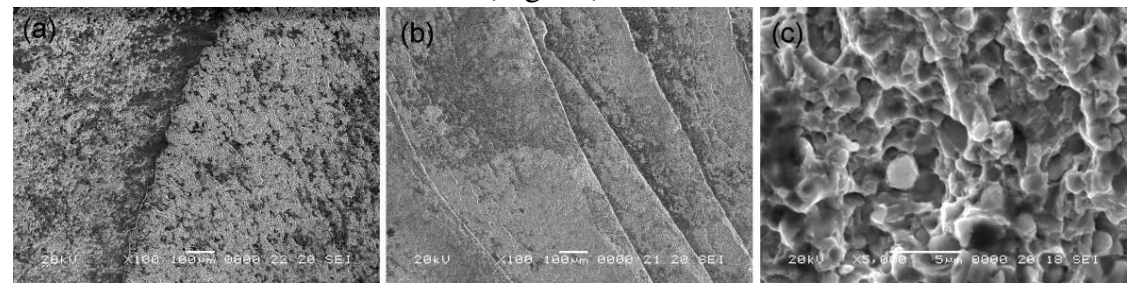

Fig. 9. SEM micrographs of PM tool showing the three fracture stages: (a) Uneven external area, (b) Beach-marks formed during crack propagation, (c) Crater of detachment area.

\section{Conclusions}

A number of design and treatment flaws would explain the acute reduction of life span of the examined components. Both tools failed due to fatigue but the fracture mechanism differed in each case. Lack of stress relief radii was observed in both D2 and PM tools. Radius has significant influence on tool service life and should be predicted from the design stage. Pronounced cross-sectional differences lead to local stress accumulation results in stress concentration and non-uniform loading, making the tool susceptible to cracking.

Both tools have been hardened uniformly. Designer should have suggested an appropriate heat treatment in order to reduce the hardness at the support points. It is estimated that a local hardness of $40 \mathrm{HRC}$, instead of $58 \mathrm{HRC}$, would increase elasticity and reduce the probability of fracture [21].

In the PM tool, a manufacturing defect, kept unmentioned by the machine shop, was detected. A ring-shaped component, made of a softer material, had been attached to the left side of the supporting system, inducing non-uniform loading conditions. In this case, the failure is mainly attributed to the manufacturing process.

The toll's poor performance could also be attributed to insufficient maintenance. In fact, the company does not keep relevant records. When not functioning, the cutting tools remain on the machine and are not protected in any way, whilst tension is never released between the successive operating cycles. It worth noting that cutting edge sharpening induces stresses on the tool surface, decreasing its fatigue resistance. This effect could be prevented applying stress relieving (i.e. heating for 8 hours at $180^{\circ}-200^{\circ} \mathrm{C}$ and then air-cooling).

In conclusion, poor design associated with improper handling is considered the main cause of the failure. In the specific PM cutting tool the break down was essentially hastened by a machining defect. 
The author acknowledgement Prof. Dr. Ing. Ionel Chicinaş from Department of Materials Science and Engineering, Technical University of Cluj-Napoca, for its contribution in electronic microscopy.

\section{References}

[1] M. Tawancy, A. Ul-Hamid, N.M. Abbas, Practical Engineering Failure Analysis. (Copyright by Marcel Dekker Inc. USA, 2004)

[2] A.K. Das, Metallurgy of Failure Analysis (McGraw-hill Publishing Comp. USA, 1997)

[3] G.A. Collins, Failure of Materials in Mechanical Design: Analysis, Prediction Prevention (Wiley-Interscience Publication. Jh. Wiley \& Sons Inc. USA, 1993)

[4] S. Jhavar S, C.P. Paul, N.K. Jain, Eng. Fail. Anal. 34, 519 (2013)

[5] N.H. Rafai1, M.A. Lajis, N.A.J. Hosni, Appl. Mech. and Mat. 465-466, 1098-1102 (Online: 2013-12-19)

[6] Z. Vagnorius, M. Rausand, K. Sorby, Eur. J. Oper. Res. 206,407 (2010)

[7] J.D. Hrisoylakis, D.I. Pantelis, The Science and Technology of Metallic Materials (Papasotirioy Ed. Athens, 1996)

[8] P.P. Sarkar, S.K. Dhua, S.K. Thakur, B. Ghosh, Eng. Fail. Anal. 46196 (2014)

[9] Tool steel Facts, Steels for Cold Work Tooling (Uddeholm Company 2013)

[10] F.K. Naumann, Failure Analysis: case, histories and methodology (ASM Int., 1983)

[11] G.A.Okolovich, Mater. Sci. Heat. Treat. 48, 233 (2006)

[12] M.R. Krishnadev, S.C. Jain, Eng. Fail. Anal. 14, 1053 (2006)

[13] C.G. Gagg, Eng. Fail. Anal. 8, 87 (2001)

[14] A.A. Oskuie, T. Shahrabi, A. Lajevardi, Eng. Fail. Anal. 28, 34 (2013)

[15] B. Bhattachayya, S. Gangopadhyaqy, B.R. Sarkar, J. Mater. Technol. 189, 167 (2007)

[16] S. Subbiah, S.N. Melkote, Mater. Sci. Eng. A474, 283 (2008)

[17] C. Scandian, T.S. Luz, J.M. Pardal, S.S.M. Tavares, J. Fail. Anal. and Preven. 15, 789 (2015)

[18] M. Knoer, K. Lange, T Altan, J. Mater. Process. Technol. 46, 57 (1994)

[19] K.D. Bouzakis, N. Michailidis, G. Skordaris, E. Bouzakis, D. Biermann, R. M'Saubi, CIRP Ann. Manuf. Techn. 61, 703 (2012)

[20] C. Chen, Y Wang, H. Ou, Y. He, X. Tang, J. Clean Prod. 64, 13 (2014)

[21] C. Mac Coemack, J. Monagham, J. Mater. Process. Technol. 117, 209 (2001)

[22] A. Jeang, Eur. J. Oper. Res. 108, 334 (1998)

[23] B. Falk, U. Engel, M. Geiger, J. Mater. Process. Technol. 80-81, 602 (1998)

[24] C.W. Wegst, Nachschlagewerk Stahlschlüssel (Verlag Stahlschlsüsel Wegst GmbH \& Co. Marbach 1980)

[25] Tool Steel Facts, Sverker 21 (Uddeholm Company 2016)

[26] Tool Steel Facts, Vanadis 6 (Uddeholm Company 2014)

[27] J. Yao, X.H. Qu, X.B. He, L. Zhang, Mat. Sci. Eng. A528, 4180 (2011)

[28] D. Statharas, J. Sideris, C. Medrea, I. Chicinaş, Eng. Fail. Anal. 18, 759 (2011)

[29] S.K. Shather, Eng. Tech. J. 27, 256 (2009) 